\title{
Hippopotamid dispersal across the Mediterranean in the latest Miocene: a re-evaluation of the Gravitelli record from Sicily, Italy
}

\author{
Roberta Martino, Johannes Pignatti, Lorenzo Rook, and Luca Pandolfi \\ Acta Palaeontologica Polonica 66 (3), 2021: s067-s078 doi:https://doi.org/10.4202/app.00838.2020
}

The first dispersal of Hippopotamidae out of Africa is recorded around $6 \mathrm{Ma}$, but this event is documented only in a few European localities. Among them, the uppermost Miocene deposits of Gravitelli in Sicily yielded particularly abundant hippopotamid remains. These specimens, published at the beginning of the 20th century, went lost during the 1908 earthquake that destroyed the city of Messina. The specimens from Gravitelli were ascribed to a new species, Hippopotamus siculus; their generic attribution was not questioned during the first half of the past century and they have not been revised in recent decades. The remains of the Gravitelli hippopotamid were mainly represented by isolated teeth and a few postcranial remains.

Morphological and dimensional characters of the specimens, such as long lower premolars, lowcrowned molars, a lower canine with longitudinal ridges and a groove on the lateral surface and the overall dimensions suggest that the Sicilian hippopotamid was characterized by plesiomorphic features. The morphology of the specimens collected from Gravitelli is similar to that of Hexaprotodon? crusafonti, Archaeopotamus harvardi, Hexaprotodon sivalensis and Hexaprotodon garyam. Hexaprotodon? siculus is also morphometrically similar to Hexaprotodon sivalensis, but the lower premolars in the former are longer and wider than in the latter. Accordingly, we provisionally refer the Gravitelli hippopotamid to the genus Hexaprotodon. Hexaprotodon? siculus is dimensionally different from the Spanish latest Miocene hippopotamid, herein referred to as Archaeopotamus crusafonti, and the two species are considered as valid taxa. The paleobiogeography of the latest Miocene hippopotamids from the Mediterranean Basin is discussed.

Key words: Mammalia, Hippopotamidae, dental morphology, Miocene, Gravitelli, Italy.

Roberta Martino [roberta.aska@gmail.com], via Ninfa, 9, Latina, Italy. Johannes Pignatti [johannes.pignatti@uniroma1.it], Dipartimento di Scienze della Terra, "Sapienza" Università di Roma, Piazzale Aldo Moro 5, 00185 Rome, Italy. Lorenzo Rook [lorenzo.rook@unifi.it] and Luca Pandolfi [luca.pandolfi@unifi.it], Dipartimento di Scienze della Terra, Università degli Studi di Firenze, Viale Giorgio La Pira 4, 50121 Florence, Italy. 
This is an open-access article distributed under the terms of the Creative Commons

Attribution License (for details please see creativecommons.org), which permits unrestricted use, distribution, and reproduction in any medium, provided the original author and source are credited.

Farf Full text $(1,049.2 \mathrm{kB})$ 